\title{
Intraosseous neurilemmoma of the cervical spine causing paraparesis and treated by resection and grafting
}

\author{
C. E. POLKEY \\ From the Neurosurgical Unit of Guy's, Maudsley, and King's College Hospitals, \\ at the Maudsley Hospital, London
}

SYNOPSIS A neurilemmoma presented as an expanding lesion of the bodies of C6 and C7 vertebrae and caused local neurological signs together with a spastic paraparesis. This tumour was treated by preliminary posterior fusion, followed by its complete removal via an anterior approach and stabilization by anterior spinal fusion. Other cases in the literature are reviewed and discussed.

Solitary lesions affecting the vertebral bodies are uncommon and present problems in regard to both diagnosis and treatment. This case report describes how such a lesion was investigated and found at operation to be a neurilemmoma probably arising from within the vertebral body. The extirpation of this lesion is described and discussed.

\section{CASE HISTORY}

A housewife, aged 34 years, was admitted to the Neurosurgical Unit in February 1974. In January 1970, after falling in snow and injuring her back and neck, she experienced pain in the neck for a few days. In June 1970 after a fall she had further pain and a radiograph showed a lesion, assumed at that time to be a fracture, in the body of C6 vertebra (Fig. 1). In April 1973 she began to have pain in the greater trochanter of the left femur which woke her at night. By December 1973 she also had pain in the right buttock and both sacroiliac regions, and she became aware that she was dragging her left foot and scuffing the toes of her left shoe. She also noticed some weakness of the left hand and a patch of numbness around the left knee. During the week before admission she experienced a band-like feeling around her upper abdomen and tightness in both legs.

Examination showed a healthy woman with no abnormalities apart from the neurological signs described below; in particular, there were none of the

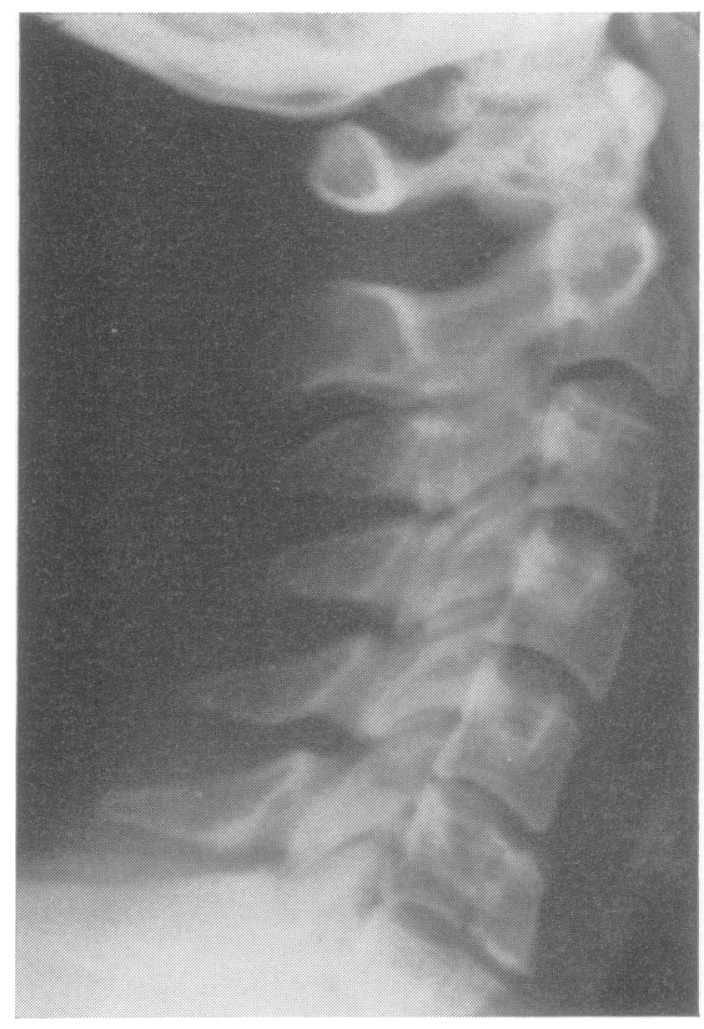

FIG. 1 Lateral radiograph of the cervical spine in June 1970 showing the pathological fracture in the body of C6 vertebra. 

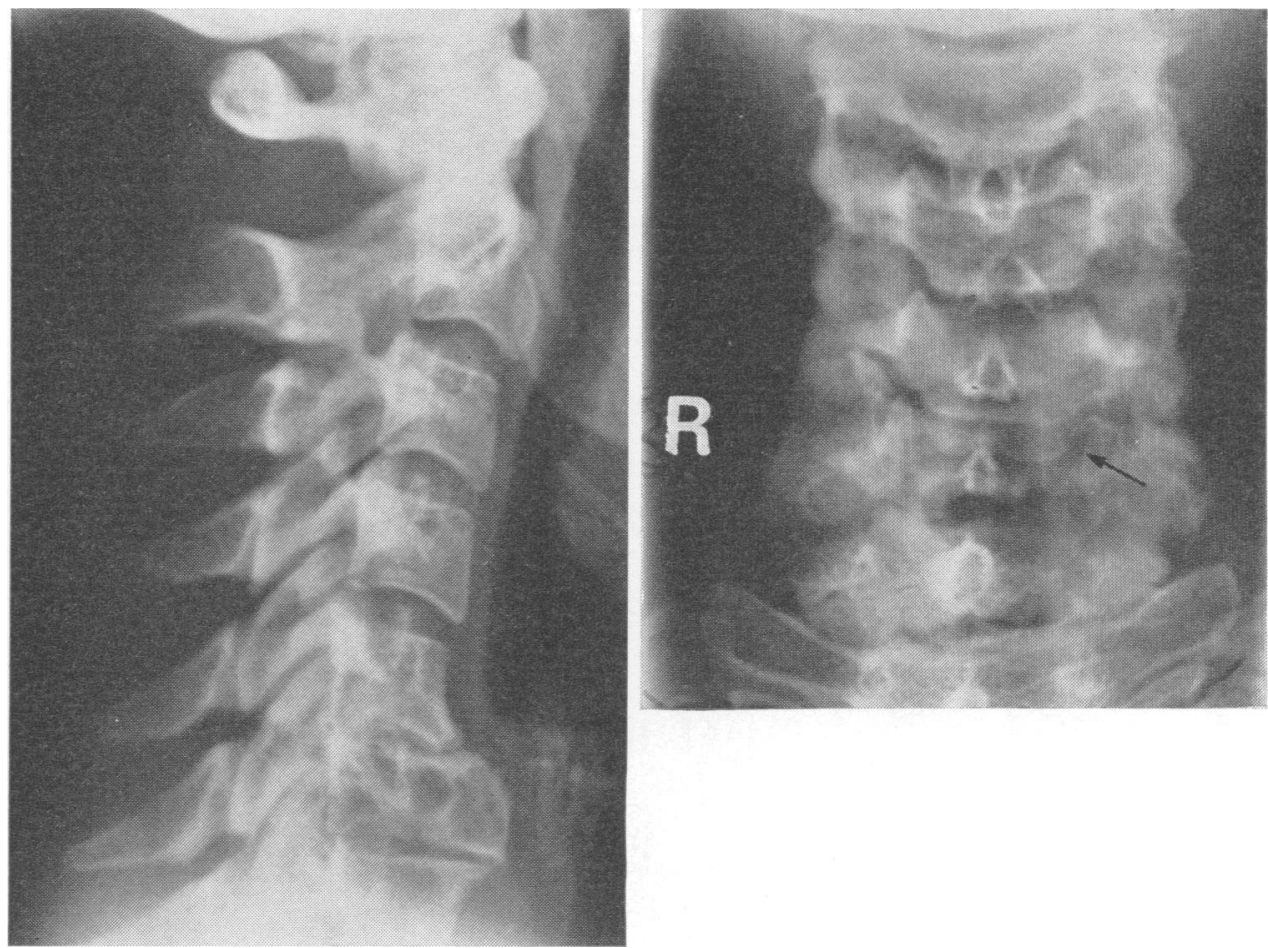

FIG. 2 (left) Lateral radiograph of the cervical spine in January 1974 showing progression of the osteolytic lesion which has now expanded the body of C6 and can also be seen in the upper half of the body of C7 vertebra. FIG. 3 (right) Anteroposterior radiograph of the cervical spine in January 1974 showing the osteolytic lesion in the bodies of C6 and C7 vertebrae, the pedicle of C6 vertebra is also involved on the left side (arrow).

stigmata of von Recklinghausen's disease. The cranial nerves were normal apart from a minimal Horner's syndrome on the left. In both upper limbs there was weakness of extension and flexion of the wrist and fingers and slight weakness of the left interosseous muscles. There was bilateral weakness of hip flexion, left more than right, and weakness of dorsiflexion of the left ankle and toes. The biceps and supinator jerks were present on both sides but both triceps jerks were absent. Both knee and ankle jerks were increased and the plantar responses were bilaterally extensor. Sensory testing revealed a slight bilateral loss of pain and tactile sensation involving the ulnar two fingers of both hands and the ulnar borders of the forearms, and extending down to the umbilicus.

Below the umbilicus pinprick became normal but light touch remained impaired. Joint position sense was impaired in the toes of both feet and vibration sense was absent in the left leg. Thus there was clinical evidence of cord compression in the lower cervical region together with bilateral nerve root involvement at $\mathrm{C} 7$ level.

INVESTIGATIONS Radiographs of the neck in January 1974 , including tomography, showed an osteolytic lesion expanding the body of C6 vertebra and the left half of the body of $\mathrm{C7}$, with some destruction of the pedicle of C6 vertebra (Figs 2 and 3). A lumbar myelogram in February 1974 showed a complete block at the lower border of $\mathrm{C7}$ vertebra, with the spinal cord pushed to the right. The lumbar CSF contained no cells, but the protein content was $1.3 \mathrm{~g} / \mathrm{l}$. A left vertebral arteriogram showed that there was no gross blood supply to the affected vertebrae from this vessel. A skeletal isotopic scan $(99 \mathrm{~m}$ Tc polyphosphate) demonstrated that the lesion was solitary. Other investigations showed a normal blood picture with a haemoglobin level of $13.5 \mathrm{~g} / \mathrm{dl}$, a white cell count of $7600 / \mathrm{mm}^{3}$ with a normal differential, and an ESR of $10 \mathrm{~mm} / \mathrm{h}$ (Westergren). The serum 


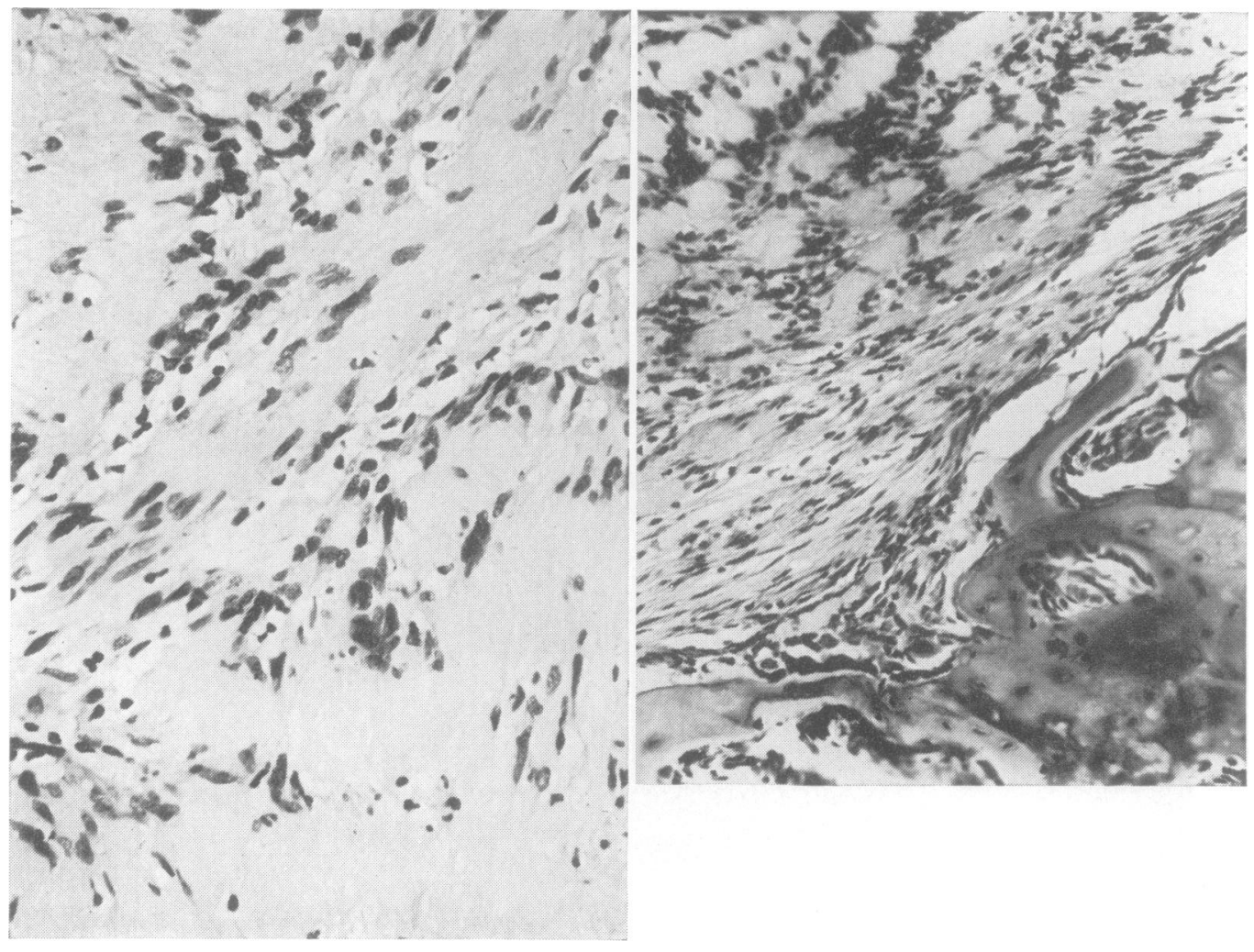

FIG. 4 Photomicrograph showing compact Antonini $A$ areas and loose vacuolated Antonini $B$ areas. The compact areas are composed of interwoven groups of elongated cells arranged in parallel with their nuclei clustered in poorly formed palisades. They contained $P A S$ positive and argyrophil filaments and patchy focal calcification of their centres was also seen. $(H$ and $E, \times 250)$. FIG. 5 (right) Section showing the intraosseous neurilemmoma (above) with reactive new bone formation around the edge (below). ( $H$ and $E, \times 160$.

electrolytes and urea were normal and the blood WR, VDRL, and Reiter's protein tests were normal.

Thus, the investigations showed an osteolytic lesion in the bodies of $\mathrm{C} 6$ and $\mathrm{C} 7$ vertebrae, crossing the C6/7 intervertebral disc space and causing an extrathecal block. The slow progression and lack of other constitutional disturbance suggested that it was probably benign and the preoperative diagnosis was an aneurysmal bone cyst.

TREATMENT As excision of the two affected vertebral bodies carried a risk of collapse of the spinal column a posterior fusion to stabilize the cervical spine was carried out on 1 March 1974. Two bone grafts (each $8 \mathrm{~cm} \times 1 \mathrm{~cm}$ ) were taken from the right iliac crest and wired into place on either side of the spines and laminae of C5 to T1 vertebrae. Three weeks later the patient was allowed home to wait until this fusion had become solid. She was readmitted on 8 May, nine weeks after the posterior fusion and she was neurologically unchanged. On $16 \mathrm{May}$, under general anaesthesia, using controlled respiration and with the patient in the supine position, a pair of Crutchfield callipers was placed on the skull for skeletal traction. A left supraclavicular incision was made in a skin crease, as for an anterior interbody fusion, the anterior aspects of the $\mathrm{C} 6$ and $\mathrm{C} 7$ vertebrae were exposed and the site of the C6/7 disc space was confirmed by a lateral radiograph taken after a needle had been put into it. As the paravertebral muscles were dissected off the anterior aspect of the bodies of $\mathrm{C} 6$ and $\mathrm{C} 7$ vertebrae an avascular, greyishbrown, nodular tumour $(2.5 \mathrm{~cm} \times 2.0 \mathrm{~cm})$ was seen protruding in places through the bone. The demarca- 


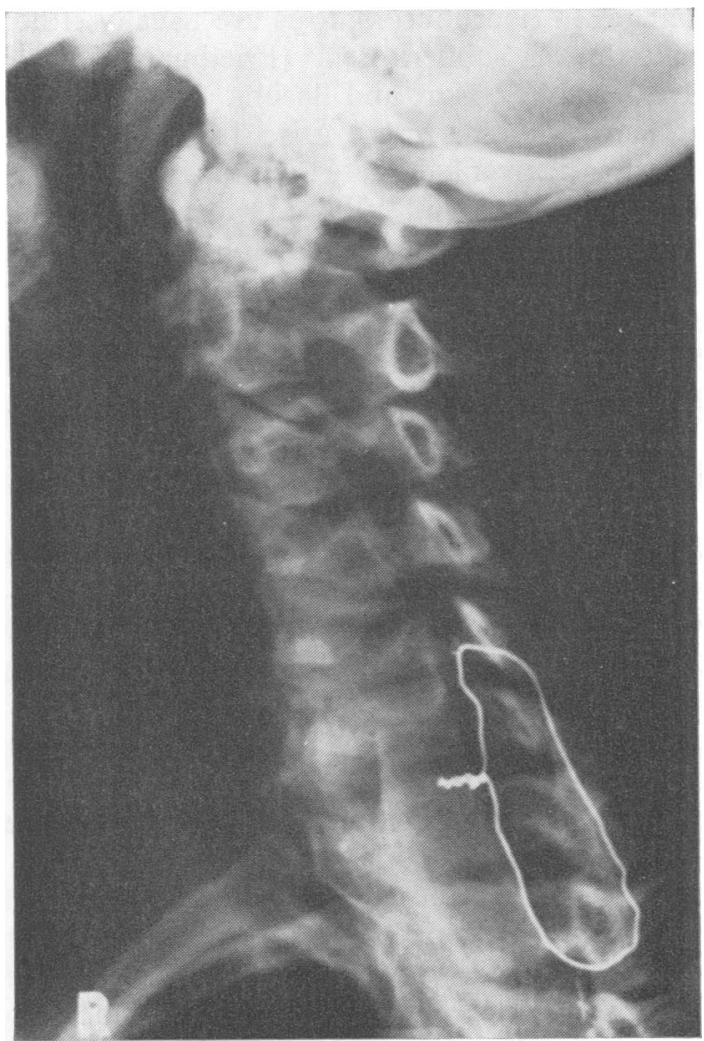

FIG. 6 Oblique radiograph of the cervical spine in October 1974. The whole anterior block can be seen lying between $C 5$ and $T 1$.

tion between this tumour and the surrounding tissues was clear and the anterior surface of the dura mater had been indented by the tumour but was intact. The tumour was removed completely, in piecemeal fashion, leaving a cavity spanning the remains of the bodies of $\mathrm{C} 6$ and $\mathrm{C} 7$ vertebrae. The epiphyseal plates of the lower end of the body of C5 vertebra and the upper end of the body of $\mathrm{T} 1$ vertebra were then scraped away. Next, a single block of bone from the left iliac crest $(3.5 \mathrm{~cm} \times 1.0 \mathrm{~cm})$ was placed neatly and firmly into the cavity between $\mathrm{C} 5$ and $\mathrm{T} 1$ vertebral bodies. Histologically, as shown in the photomicrograph (Figs 4 and 5) this tumour proved to be a neurilemmoma (Dr Anne Marshall).

To prevent flexion of the neck, light skeletal traction $(1 \mathrm{~kg})$ was applied for four weeks. During this time her spastic paraparesis receded and serial lateral radiographs of the neck showed that the graft remained in good position. Then over 10 days she was mobilized using a Plastazote collar and, in late June, a soft collar was substituted to restrict flexion of her neck. It then became possible to see the graft in both oblique and lateral radiographic projections and these showed it to be in good position (Fig. 6). Six weeks after the definitive operation, examination revealed some weakness of the left triceps with slight weakness of extension of the left wrist and fingers, possibly due to damage to the $\mathrm{C} 7$ anterior nerve root at operation. However, this was recovering. The left triceps jerk remained absent. There was also a small area of impairment of pinprick in the left C8 dermatome. The only evidence of her paraparesis was bilateral extensor plantar responses. Twelve weeks after her operation her walking was completely normal and her other signs continued to improve.

\section{DISCUSSION}

In a series of 34950 neurosurgical admissions, in Bucharest (Arseni et al., 1959) only $350(1 \%)$ were patients with tumours affecting the vertebral column, which is an index of the rarity of these lesions. Also the majority affect the lower dorsal and lumbar spine and, among this group of 350 , only $28(8 \%)$ were in the cervical spine. Likewise, in the series of 413 apparently solitary lesions of the vertebral column described from the Mayo Clinic by Cohen et al. (1964), $45(11 \%)$ were in the cervical spine. Metastatic lesions formed a sizeable proportion of these tumours. In the series of Arseni et al. (1959) they formed $66 \%$ of all tumours affecting the vertebral column. In the series of Cohen et al. (1964) of apparently solitary lesions affecting vertebrae, metastatic deposits formed $29.2 \%$ of the total, and $17.7 \%$ of the tumours in the cervical vertebrae.

Because of their rarity (less than $0.1 \%$ of all bone tumours in the series of Arseni et al., 1959), these cervical vertebral lesions pose a considerable problem in differential diagnosis. If the common tumours found by Cohen and colleagues are considered, we would need to distinguish between a metastatic deposit, a chordoma, a solitary myeloma, a chondrosarcoma, an osteoid osteoma and an aneurysmal bone cyst, with the addition (from the 103 primary tumours in vertebrae in the series of Arseni et al.) of giant cell tumour and angioma.

Several of these possibilities can be easily excluded; angioma, myeloma and chondrosarcoma have typical radiographic appearances 
which were not seen in the present case. Giant cell tumour (osteoblastoma) rarely occurs above the sacrum; 14 of 16 cases reported by Cohen et al. (1964) were in the sacrum. A solitary myeloma deposit is more difficult since this may occur in a vertebra without the disturbances of plasma proteins found in multiple myelomatosis. This was the case in 12 of the 20 patients described by Griffith (1966).

This, therefore, leaves the aneurysmal bone cyst, the osteoid- osteoma, and the chordoma, with the very remote possibility, because of the long history and lack of constitutional disturbance, of a metastatic deposit. Both the osteoid osteoma and the aneurysmal bone cyst are more common in men than women and tend to appear before the age of 30 years (MacCarty et al., 1961). The chordoma, also more common in men, tends to present at an older age, between 30 and 60 years. Among the remaining lesions which occurred singly and in pairs in the cervical spine in the series of Cohen et al. (1964) was Ewing's tumour (which has a characteristic radiographic appearance) lymphoma and fibrous dysplasia of bone. A number of other lesions, including the eventual diagnosis of neurilemmoma, appeared in other parts of the spinal column. In this case the most likely preoperative diagnosis was thought to be an aneurysmal bone cyst. A neurilemmoma arising within bone is rare. In his monograph on bone tumours Jaffe (1958) describes only seven cases, five from the world literature and two of his own. Among a series of 3987 primary bone tumours of all parts of the skeleton described from the Mayo Clinic by Fawcett and Dahlin (1967) there were only seven neurilemmomas. These authors excluded the six neurilemmomas described by Cohen et al. (1964) from their solitary vertebral lesions because they felt that the tumours had not arisen from within the vertebral body, although in two cases the radiological description suggests the contrary. In the most recent review by Spjut et al. (1970) of neurilemmoma arising within bone, 40 cases from the world literature are mentioned but only one of these was in the spine. Jaffe (1958) describing the osseous abnormalities associated with neurofibromatosis makes no mention of neurilemmoma, and in the 40 cases reviewed by Spjut et al. (1970) only one neurilemmoma is in a patient with neurofibromatosis. The cystic bone changes of neurofibromatosis are usually either multiple or subperiosteal (Friedmann, 1944; Hensley, 1953; Hart and Basom, 1958).

Neurilemmoma must arise from the nerve sheaths and over half these tumours in man occur in the mandible (Jaffe, 1958; Owen, 1969; Spjut et al., 1970). This has been attributed to the long intraosseous course of the mental branch of the inferior dental nerve. Small nerves have been described in the vertebral bodies of man and animals which could give rise to neurilemmoma (Pedersen et al., 1956; Stilwell, 1956; Sherman, 1963).

A careful search of recent literature, together with the present case, revealed nine cases of neurilemmoma possibly arising within a vertebral body. Of these, six cases were described by Cohen et al. (1964) and one each by Orf (1970) and Dickson et al. (1971). The present case was the only one in the cervical spine. Of the other eight, one was in a thoracic vertebra, four in lumbar vertebrae, and the remaining three in the sacrococcygeal vertebrae.

They had several clinical features of interest. They all had long histories, extending over several years. Seven were women, and two were in men. Seven presented with pain, the other two presented with neurological symptoms. Five had neurological signs when they were first seen, four did not. One had the features of von Reckling hausen's disease (neurofibromatosis). The radiological appearances in these cases were variable. In our case and that of Orf (1970) the lesion spanned a disc space involving two vertebral bodies. In the others only one body was involved. The lesion in our case was thought to be an aneurysmal bone cyst. The radiological features of these cases, as described, seem to fall into two groups perhaps related to their point of origin. In one group there is gross destruction of the vertebral body, lamina and pedicle from an extrinsic expanding lesion, as in four cases described by Cohen et al. (1964) and in Orf's case where $L 1$ and $L 2$ vertebrae were involved. In the remaining group of three cases there was an erosive expanding lesion within the vertebral body, with sclerotic margins.

This is seen in the present case and corresponds nicely with the microscopical appearance of the decalcified specimen (Fig. 5). This also resembles the radiographic appearance of neuri- 
lemmoma in other bones, such as the various long bones (see Gross et al., 1939; Seth et al., 1963).

A historical review of the various surgical approaches to the vertebral body is given by Verbiest (1968) who first used the anterior approach with bone grafting for an aneurysmal bone cyst in the body of L5 vertebra in 1942, and for a chordoma in the body of T12 vertebra in 1946.

The first anterior approach in the cervical region for tumour, followed by bone graft is described by Cloward (1960). He had a patient with a neurofibroma of the left $\mathrm{C} 3$ nerve root previously treated by posterior laminectomy, and this tumour had gone on to destroy the bodies of $\mathrm{C} 3$ and $\mathrm{C} 4$ vertebrae. He removed the tumour and filled the space with cadaver iliac bone graft. At the time the body of $\mathrm{C} 4$ vertebra had collapsed and dislocated posteriorly into the spinal canal. It is, of course, to prevent a similar difficulty should the anterior fusion have failed, that the preliminary posterior fusion was carried out on this patient. Bailey and Badgley (1960) performed a similar posterior fusion with wire between $\mathrm{C} 2$ and $\mathrm{C} 7$ vertebrae before using an anterior approach and graft of autogenous iliac crest bone, to treat a giant cell tumour which had eroded the bodies of $\mathrm{C} 4$ and $\mathrm{C} 5$ vertebrae. A two stage procedure with an iliac bone graft was also used by Buck and Bailey (1969) to treat an aneurysmal bone cyst in a cervical vertebral body. Finally, Martin and Williamson (1970) have employed this technique in two cases where cervical vertebrae were eroded by malignant disease.

I wish to thank Mr Murray Falconer whose case this was, Dr Anne Marshall of the Department of Neuropathology of the Institute of Psychiatry, who prepared the histological description and photomicrographs of the tumour, and Professor H. Sissons, who confirmed her histological diagnosis. Mr J. S. Batchelor assisted with the positioning of the graft, and Mr R. C. F. Catterall also helped us. The prints of the radiographs were prepared in the Department of Medical Photography at Guy's Hospital.

\section{REFERENCES}

Arseni, C. N., Simionescu, M. D., and Horwath, L. (1959). Tumors of the spine. A follow-up study of 350 patients with neurosurgical considerations. Acta Psychiatrica et Neurologica Scandinavica, 34, 398-410.
Bailey, R. W., and Badgley, C. E. (1960). Stabilization of the cervical spine by anterior fusion. Journal of Bone and Joint Surgery, 42A, 565-594.

Buck, R. E., and Bailey, R. W. (1969). Replacement of a cervical vertebral body for aneurysmal cyst. A case report. Journal of Bone and Joint Surgery, 51A, 1656-1659.

Cloward, R. B. (1960). Destruction of cervical vertebra by solitary neurofibroma. Report of a case with quadriplegia. Journal of Neurosurgery, 17, 511-519.

Cohen, D. M., Dahlin, D. C., and MacCarty, C. S. (1964). Apparently solitary tumors of the vertebral column. Proceedings of the Staff Meetings of the Mayo Clinic, 39, 509528.

Dickson, J. H., Waltz, T. A., and Fechner, R. E. (1971). Intraosseous neurilemmoma of the third lumbar vertebra. Journal of Bone and Joint Surgery, 53A, 349-355.

Fawcett, K. J., and Dahlin, D. C. (1967). Neurilemmoma of bone. American Journal of Clinical Pathology, 47, 759-765.

Friedman, M. M. (1944). Neurofibromatosis of bone. American Journal of Roentgenology, 51, 623-630.

Griffith, D. Ll. (1966). Orthopaedic aspects of myelomatosis. Journal of Bone and Joint Surgery, 48B, 703-728.

Gross, P., Bailey, F. R., and Jacox, H. W. (1939). Primary intramedullary neurofibroma of the humerus. Archives of Pathology, 28, 716-718.

Hart, M. S., and Basom, W. C. (1958). Neurilemmoma involving bone. Journal of Bone and Joint Surgery, 40A, 465468.

Hensley C. D. Jr. (1953). The rapid development of a 'subperiosteal bone cyst' in multiple neurofibromatosis. Case report. Journal of Bone and Joint Surgery, 35A, 197-203.

Jaffe, H. L. (1958). Bone lesions associated with neural tumors. In Tumors and Tumorous Conditions of the Bones and Joints. pp. 240-255, Kimpton: London.

MacCarty, C. S., Dahlin, D. C., Doyle, J. B. Jr, Lipscomb, P. R., and Pugh, D. G. (1961). Aneurysmal bone cysts of the neural axis. Journal of Neurosurgery, 18, 671-677.

Martin, N. S., and Williamson J. (1970). The role of surgery in the treatment of malignant tumours of the spine. Journal of Bone and Joint Surgery, 52B, 227-237.

Orf, G. (1970). Zur Klinik und Morphologie eines infiltrativen Spinalneurinoms. Archiv für Psychiatrie und Nervenkrankheiten, 213, 396-407.

Owen, L. N. (1969). Tumours arising from fibrous, fatty, neurological or undifferentiated connective tissue. In Bone Tumours in Man and Animals, pp. 80-98. Butterworths: London.

Pedersen, H. E., Blunck, C. F. J., and Gardner, E. (1956). The anatomy of lumbosacral posterior rami and meningeal branches of spinal nerves (Sinu-vertebral nerves). Journal of Bone and Joint Surgery, 38A, 377-391.

Seth, H. N., Rao, B. D. P., and Kathpalia, P. M. L. (1963). Neurilemmoma of bone. Report of a case. Journal of Bone and Joint Surgery, 45B, 382-383.

Sherman M. S. (1963). The nerves of bone. Journal of Bone and Joint Surgery, 45A, 522-528.

Spjut, H. J., Dorfman, H. D., Fechner, R. E., and Ackerman, L. V. (1970). Tumors of bone and cartilage. Armed Forces Institute of Pathology. Atlas of Tumor Pathology. Second Series, fascicle 5, pp. 341-346. Armed Forces Institute of Pathology: Washington.

Stilwell, D. L., Jr. (1956). The nerve supply of the vertebral column and its associated structures in the monkey. Anatomical Record, 125, 139-169.

Verbiest, H. (1968). Basic principles of surgery upon the anterior portion of the spine. Psychiatria, Neurologia, Neurochirugia, 71, 115-131. 